The layout is attractive, and the printing and production are excellent. The use of regular hexagons for benzenoid compounds is to be commended. Only one formula has been noted as in error - that, of terylene (p. 416). The personalities of organic chemistry are portrayed in brief biographical footnotes that accompany the first mention of a "named reaction", etc. There is an appendix on the pronunciation (American style) of organic chemical words which is scarcely necessary if the text is to be used in conjunction with a lecture course.

A chapter devoted to organic peroxides, autoxidation and antioxidants is a commendable innovation, while the chapter on organometallic compounds contains an account of the newer developments in organosilicon chemistry. The chapter on stereoisomerism contains an admirable introduction to the topics of absolute and relative configuration. The description of the boat and chair conformations of cyclohexane as cis and trans forms (p. 562) is deprecated. The cis-trans terminology was introduced to describe the isomerism, about an ethylenic bond and within a single plane, exemplified by maleic and fumaric acids. The subsequent extension of this terminology to describe the isomerism in three dimensions of di-substituted cycloalkanes, etc., was unwarranted, but has become sanctioned by long usage. 'T'he further extension of this terminology to include the boat and chair conformations of cyclohexane would confuse fundamentally different phenomena and would seriously weaken the value of established cis-trans usage. This is a criticism of a point of detail, however, and the book as a whole can be warmly recommended as a reasonably priced text-book of organic chemistry for students in British universities. S. H. HARPER

\section{LABORATORY TECHNIQUES IN THE TESTING OF MILK}

\section{Milk Testing}

The Laboratory Control of Milk. By Dr. J. G. Davis. Pp. 260. (London: Dairy Industries, Ltd., 1951.) 15s. 7 HIs book is described in the preface as a "practical manual for the bench worker", but many, including the reviewer, will no doubt also keep it as a ready form of reference on all dairy subjects where laboratory technique of a specialized nature is required. The manual is not merely a collection of methods, for Dr. J. G. Davis has given the reader the benefit of his many years of experience both as a practical chemist and bacteriologist, and also as a technical director of one of the largest dairy companies in Great Britain. The methods for the control of the quality of milk are therefore one of the book's main purposes. Many of the methods embodied in British Standards have been quoted in toto. Since these are the result of collaborative study by dairy chemists, public analysts and independent analysts, they can be accepted as authoritative. Dr. Davis can quote from personal knowledge of the many discussions and tests which preceded the formulation of these methods, since he is a member of long standing of the relevant committees of the British Standards Institution.

Dr. Davis has described a number of interesting personal observations which may be new to the reader ; for example, the experience of a milk having a 'disgusting' odour which changed to that suggesting mushrooms in a few hours, and which finally vanished completely. It is to be hoped that the bench worker will profit from the many references in the text, for these are a mine of information for the willing searcher. How many, however, will realize the possibilities of Meihuizen's oven, or trouble to look up the reference when told on p. 103, "For a description of an oven designed for the determination of moisture see Meihuizen (1929)"'? Several tobacco laboratories and my own laboratory have adopted this oven, which passes evenly a forced draft of air heated, and if necessary dried, at a predetermined temperature over all the samples in a cylindrical oven, provision being made for evacuating if required.

Prominence has been given to the freezing-point depression as the most reliable guide to the presence of added water. Dr. Davis has given a well-reasoned and unbiased review of the literature on the subject, rightly pointing out the empirical nature of the Hortvet test. In his remarks on the use of sugar solutions for testing the accuracy of the thermometer, I could have wished that the operator in possession of a thermometer calibrated by the National Physical Laboratory were also told that, with the aid of such an instrument as a standard of temperature, sugar solutions could even more usefully be used as a check on technique. The false view is currently held in some quarters that the freezing-point depression of milk is measured in 'Hortvet' degrees. On the contrary Hortvet used, as his standard, thermometers calibrated by the U.S. Bureau of Standards on the International Temperature Scale. When an empirical test relies on accurate standardization of apparatus, technique, etc., and cannot be checked by any absolute method, it is of fundamental importance that the one factor which can be standardized independently, namely, the thermometer, should have the benefit of this standardization.

As might be expected from a bacteriologist of Dr. Davis's standing, particular attention has been devoted to modern bacteriological testing of milk. His summary of comparisons of various bacteriological tests in the form of table on p. 119 is the outcome of many years of careful observation. The resazurin test, of which Dr. Davis has made a special study, is described with a wealth of practical detail, and with many hints on the correct interpretation of results. An unusual feature of such a book is a chapter on the organization and equipment of a dairy control laboratory, and the author has obviously given careful thought to the suitable design of such laboratories. Many of his ideas could, in fact, usefully be employed in any modern analytical laboratory.

For a book so packed with data, the errors are comparatively few, and fortunately these will not worry the bench worker. On p. 31, fat is described as having a specific gravity of 0.93 per cent. While sodium thiosulphate is employed to break up any mercury-amino body in Kjeldahl determinations, it is scarcely necessary to use it with a copper-selenium catalyst (p. 59). The inexperienced laboratory worker might be confused by the wording in the directions for preparation of standard solutions, as in some cases this suggests that the reagent is added to a volume of water and not dissolved and the solution bulked to the volume (pp. 230, 231).

The book is profusely illustrated and contains such a mass of useful data that it will surely find an indispensable place in the library of all dairy laboratories and form a most ready guide to all analysts who have to test milk and its products. 